\title{
Journal of the Experimental Analysis of Behavior
}

\section{SPECIAL ISSUE ON THE EXPERIMENTAL ANALYSIS OF COGNITION}

\section{CONTENTS (November 1989)}

K. G. White, D. McCarthy, \& E. Fantino. Cognition and behavior analysis.

D.S. Blough. Contrast as seen in visual search reaction times.

R. S. Bhatt \& E. A. Wasserman. Secondary generalization and categorization in pigeons.

D. R. Thomas \& E. K. Schmidt. Does conditional discrimination leaming by pigeons necessarily involve hierarchical relationships?

M. R. D'Amato \& M. Colombo. On the limits of the matching concept in monkeys (Cebus apella).

A. A. Wright, R. G. Cook, \& D. F. Kendrick. Relational and absolute stimulus learning by monkeys in a memory task.

J. G. Fetterman \& D. MacEwen. Short-term memory for responses: The "choose small" effect.

D.S. Grant. Use of an ambiguous-sample procedure to establish a cue to forget in pigeons.

K. D. Allen \& K. A. Lattal. On conditioned reinforcing effects of negative discriminative stimuli.

C. P. Shimp, S. L. Sabulsky, \& L. J. Childers. Preference for starting and finishing behavior patterns.

J. Myerson, S. Hale, R. Hirschman, C. Hansen, \& B. Christiansen. Global increase in response latencies by early-middle age: Complexity effects in individual performances.

M. Sidman, C. K. Wynne, R. W. Maguire, \& T. Barnes. Functional classes and equivalence relations.

L. J. Hayes, S. Thompson, \& S. C. Hayes. Stimulus equivalence and rule following.

B. Lowenkron. Instructional control of generalized relational matching in children.

K. Cheng \& W. A. Roberts. Timing multimodal events in pigeons.

M. E. Rilling \& T. L. LaClaire. Visually guided catching and tracking skills in pigeons: A preliminary analysis.

M. T. Turvey, H. Y. Solomon, \& G. B'Irton. An ecological analysis of knowing by wielding. (Theoretical Article)

J. T. Wixted. Nonhuman short-term memory: A quantitative reanalysis of selected findings. (Theoretical Article)

E. J. Kehoe. Connectionist models of lzarning: A tutorial. (Theoretical Article)

J. T. Wixted. The vocabulary of remembering: A review of Kendrick, Rilling, and Denny's Theories of Animal Memory.

Available as a single issue for $\$ 15.00$ (postpaid).

Until 31 December 1989, you may still enter your subscription for all six 1989 issues: $\$ 65.00$ institutions; $\$ 20.00$ individuals (personal use only). Subscribers outside the U.S. should add $\$ 6.00$ for postage. After the end of the year, subscribers within the U.S. should add $\$ 4.00$ shipping for all six 1989 issues.

1990 Rates

$\$ 70.00$ Institutions

24.00 Individuals (personal use only)

12.00 Fulltime students (personal use only)
Send orders and payment to:

Kay Dinsmoor, JEAB

Psychology Department

Indiana University

Bloomington IN 47405-1301

U.S.A. 


\title{
CATEGORICAL PERCEPTION
}

\section{The Groundwork of Cognition \\ Edited by Stevan Harnad}

How do we sort the objects, people, events and ideas in the world into their proper categories? What transforms the "blooming, buzzing confusion" that enters our eyes and ears when we are born into the orderly world we experience and interact with?

This most basic of questions about human (and animal) perception and cognition is the subject of this exhaustive survey of the findings in a diversified area of research known as "categorical perception." With contributions from a wide range of international experts, this volume brings together all the known examples of categorical perception, in humans and animals, infants and adults, in all the sense modalities: hearing, seeing and touch. The findings are then interpreted in terms of the available cognitive and neuroscientific theories of how categorical perception is accomplished by the brain.

This research on our elementary perceptual and psychophysical categories is then integrated with the work on higher-order categories: objects, patterns, abstract concepts. From a focus on the most thoroughly investigated case of categorical perception - speech perception - the book proceeds to an integrative view of categorization in general.

Categorical Perception will be of interest to cognitive scientists, neuroscientists, developmental and comparative psychologists, behavioral biologists, linguists, anthropologists and philosophers-and anyone concerned with category representation.

$1987 \quad 599 \mathrm{pp} . \quad 26758-7 \quad \$ 59.50$

\section{CONTENTS}

\section{Introduction \\ Psychophysical and Cognitive Aspects of Categorical Perception: A Critical Overview} Stevan Harnad

Psychophysical Foundations of Categorical Perception

Categorical Perception: Some Psychophysical Models Richard E. Pastore

Beyourd the Categorical/Continuous Distinction: A Psychophysical Approach to Processing Modes Neil A. Macmillan

Categorical Perception of Speech

Phonetic Category Boundaries Are Flexible Bruno H. Repp \& Alvin H. Liberman

Auditory, Articulatory and Learning Explanations of Categorical Perception in Speech Stuart Rosen \& Peter Howell

On Infant Speech Perception and the Acquisition of Language Peter D. Eimas, Joanne L. Miller, $\checkmark$ Peter W. Jusczyk

Models for Specch CP

Neural Models of Speech Perception: A Case History Robert E. Remez

On the Categorization of Speech Sounds Randy L. Diehl $\&$ Keith $R$. Kluender

Categorical Partition: A Fuzzy-Logical Model of Categorization Behavior Dominic W. Massaro $\mathrm{CP}$ in Other Modalities and Other Species

Perceptual Categories in Vision and Audition Marc H. Bornstein

Categorical Perception of Sound Signals: Facts and Hypotheses from Animal Studies Guenther Ehret

A Naturalistic View of Categorical Perception Charles T. Snowdon

The Special-Mechanisms Debate in Speech Perception: Nonhuman Species and Nonspeech Signals Patricia K. Kuhl

Brain Mechanisms in Categorical Perception Martha Wilson

Psychophysical Indices of $\mathbf{C P}$

Electrophysiological Indices of Categorical Perception for Speech Dennis L. Molfese

Evoked Potentials and Colour-Defined Categories D. M. Regan

Higher-Order Categories

Categorization Processes and Categorical Perception Douglas L. Medin \& Lawrence W Barsalou

Developmental Changes in Category Structure Frank C. Keil G Michael H. Kelly

Spatial Categories: The Perception and Conceptualization of Spatial Relations Ellen Bialystok \& David R. Olson

Cognitive Foundations

Category Induction and Representation Stevan Hamad

COMMENTS

"CATECORICAL PERCEPTION offers a fine sample of the state of the art. Anybody who cares about cognitive science should have this stuff at his fingertips."

Jerry A. Fodor, Philosophy Department, CUNY Craduate Center

"II am] very impressed by the magnitude and quality of the general enterprise [CATECORICAL PERCEPTION is] an important contribution to a fundamental problem in cognitive psychology."

George A. Miller. Psychology Department, Princeton University

"[A]n impressive volume. Hamad's introduction is a particularly clear, economical and thorough survey of the field, its current state and its importance, in his usual crisp and entertaining style."

Patrick J. Hayes, Computer Science Department, Stanford University

"CATECORICAL PERCEPTION is essential reading for anyone interested in how we categorize what we perceive."

Philip N. Johnson-Laird, MRC Applied Psychology Unit, Cambridge

\author{
A bookstores or order from \\ Cambridge University Press \\ 32 East 57 th Street, NY, NY 10022 \\ Cambridge toll-free numbers for orders only: \\ 800-872-7423, outside NY State. 800-227-0247, NY State only. \\ MasterCard and Visa accepted.
}




\section{Journal of EXPERIMENTAL AND THEORETICAL ARTIFICIAL INTELLIGENCE}

\section{EDITORS}

Eric Dietrich

Dept of Philosophy, Program in Philosophy

and Computer \& Systems Sciences

State University of New York

Binghampton NY 13901, USA

Chris Fields

Computing Research Laboratory

New Mexico State University

Box 3CRL

Las Cruces NM 88003-0001, USA

The aim of JOURNAL OF EXPERIMENTAL AND THEORETICAL ARTIFICIAL INTELLIGENCE (JETAI) is to advance scientific research in artificial intelligence (Al) by providing a public forum for the presentation, evaluation and criticism of research results, the discussion of methodological issues, and the communication of positions, preliminary findings and research directions. Work in all subfields of $\mathrm{Al}$ research, including work on problem solving, perception, learning, knowledge representation, memory and neural system modelling will be within the scope of JETAI.

- Through editorial statements and editorial policy, JETAI will encourage AI research that adopts a scientific rather than engineering methodology.

- JETAI will provide a forum for an active and lively discussion of foundational and methodological issues in $\mathrm{AI}$ research and for critical discussions of results and techniques published either in JETAI or elsewhere in the $A I$ or cognitive science literature.

- JETAI will publish the broad range of $\mathrm{AI}$ research quickly - the Editors will strive to maintain a three month turnaround time between submission and a publication decision.

\section{Contents of inaugural issues}

Minds, Machines and Searle, Stevan Harnad - Explanation-based Learning, B. J. Krawchuk and I. A. Witten - Recognition and Classification of Concepts, F. Gomez and C. Segami

- Exploring the No-function-in-structure Principle, A. Keuneke and D. Allemang.

Publisher: Taylor \& Francis

Subscription Information

Volume 1 (1989)

Institutional Rate:

$$
\text { US } \$ 120
$$



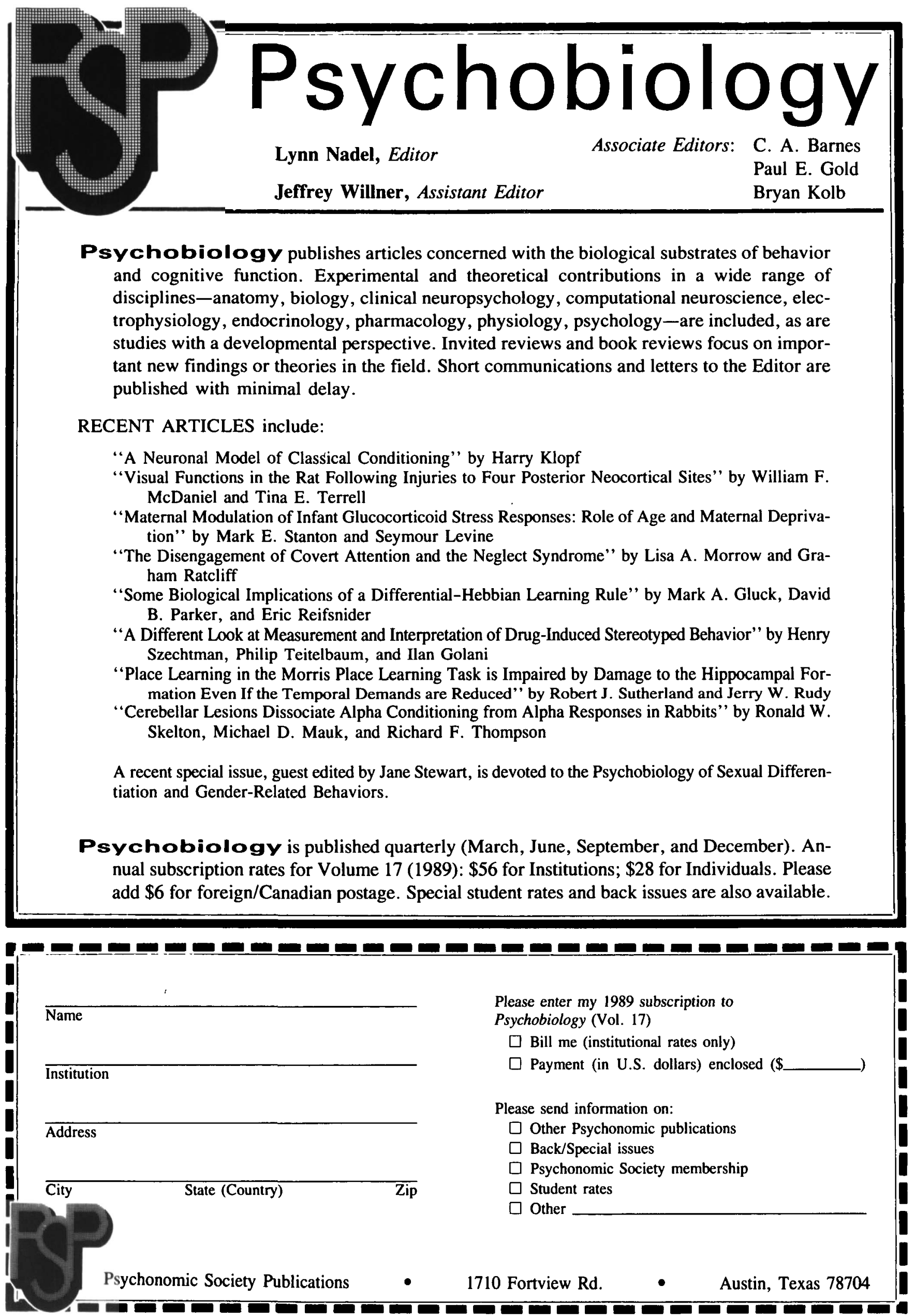


\title{
Development and Psychopathology
}

Development and Psychopathology is the new international multidisciplinary journal devoted to the publication of original empirical, theoretical and review papers which address the interrelationship of normal and pathological development in adults and children. The journal will be published by Cambridge University Press beginning in 1989. Editor Dante Cicchetti of the University of Rochester and Deputy Editor Barry Nurcombe of Brown University and Bradley Hospital are joined by a distinguished international Board of Editors.

This new journal is intended to serve and integrate the emerging field of developmental psychopathology which strives to understand patterns of adaptation and maladaptation throughout the life span.

Explorations of abnormal functioning in the social, emotional, cognitive, linguistic and biological domains help to clarify normal developmental processes. Reciprocally, elucidations of principles of normal development help to broaden our understanding of psychopathological conditions.

Development and Psychopathology strongly encourages contributions from a wide array of disciplines because an effective developmental approach to psychopathology necessitates a broad synthesis of knowledge. Articles will address, for example, the causes and effects of genetic, ontogenetic, biochemical, cognitive or socioeconomic factors in developmental processes with relevance to various psychopathological conditions. The journal will also seek articles on the processes underlying the adaptive outcomes in populations "at risk" for psychopathology.

Development and Psychopathology' is of vital interest to

- Psychologists

- Psychiatrists
- Social scientists

- Neuroscientists

- Pediatricians
- Educational researchers

Manuscripts should be submitted in triplicate to:

\author{
Dante Cicchetti, PhD \\ Mt. Hope Family Center \\ University of Rochester \\ 187 Edinburgh Street \\ Rochester, NY 14608. USA
}

(716) 275-2991

\section{Cambridge University Press}

32 East 57th Street. New York. NY 10022. USA

The Edinburgh Bldg.. Shaftesbury Rd..

Cambridge CB2 2RU. England 


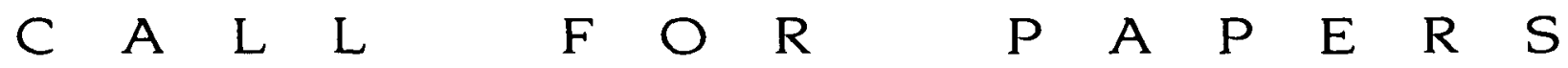 Investigators in Psychology, Neuroscience, Behavioral Biology, and Cognitive Science}

Do you want to:

- draw wide attention to a particularly important or controversial piece of work?

- solicit reactions, criticism, and feedback from a large sample of your peers?

- place your ideas in an interdisciplinary, international context?

\section{Behavioral and Brain Sciences}

an extraordinary journal, provides a special service called Open Peer Commentary to researchers in any area of psychology, neuroscience, behavioral biology, or cognitive science.

Papers judged appropriate for Commentary are circulated to a large number of specialists who provide substantive criticism, interpretation, elaboration, and pertinent complementary and supplementary material from a full cross-disciplinary perspective.

Article and commentaries then appear simultaneously with the author's formal response. This BBS "treatment" provides, in print, the exciting give and take of an international, interdisciplinary seminar.

The editor of BBS is calling for papers that offer a clear rationale for Commentary, and also meet high standards of conceptual rigor, empirical grounding, and clarity of style. Contributions may be ( 1 ) reports and discussions of empirical research of broader scope and implications than might be reported in a specialty journal; (2) unusually significant theoretical articles that formally model or systematize a body of research; and (3) novel interpretations, syntheses or critiques of existing theoretical work.

Although the BBS Commentary service is primarily devoted to original unpublished manuscripts, at times it will be extended to précis of recent books or previously published articles.

Published quarterly by the Cambridge University Press. Editorial correspondence to: Stevan Harnad, Editor, BBS, Suite 240, 20 Nassau Street, Princeton, NJ 08542. All other correspondence to BBS, Journals, Cambridge University Press, 32 E. 57th Street, New York, NY 10022.
"[ BBS's corrected 1982 impact factor of 6.370$]$ places BBS in third place [out of 1300 journals indexed] . . . in the SSCI Journal Citation Reports ... an impressive position for a journal that was then in only its fifth year of publication. By the next year, 1983, the citation impact factor for the target articles in BBS was 7.577 . . . now ahead of any other psychology journal. Even more germane to the question of the value of peer open commentary ... the total of 119 citations to the commentaries was greater than the total citations to over $91 \%$ of the journals reported in SSCI . . [G]ood scientists recognize that science progresses most rapidly by building on the ideas and observations of others, by its self-correcting nature, and by the free interaction of competing ideas and evidence."

American Psychologist

“. . . superbly presented . . the result is practically a vade mecum or Who's Who in each subject. [Articles are] followed by pithy and often (believe it or not) witty comments questioning, illuminating, endorsing or just plain arguing ... I urge anyone with an interest in psychology, neuroscience, and behavioural biology to get access to this journal."

New Scientist

"The field covered by BBS has often suffered in the past from the drawing of battle lines between prematurely hardened positions: nature $v$. nurture, cognitive $v$. behaviourist ... [BBS] has often produced important articles and fascinating interchanges . . . the points of dispute are highlighted if not always resolved, the styles and positions of the participants are exposed, and mutual incomprehension is occasionally made very conspicuous . . . commentaries are often incisive, integrative or bring highly relevant new information to bear on the subject."

Nature

"Care is taken to ensure that the commentaries represent a sampling of opinion from scientists throughout the world. Through open peer commentary, the knowledge imparted by the target article comes more fully integrated into the entire field of the behavioral and brain sciences. This contrasts with the provincialism of specialized journals ..."

Eugene Garfield, Current Contents.

“. . . open peer commentary... a allows the reader to assess the 'state of the art' quickly in a particular field. The commentaries provide a 'who's who' as well as the content of recent research."

Journal of Social and Biological Structures

“... presents an imaginative approach to learning." Library Jourmal 


\section{Cambridge University Press}

Thinking and Deciding

Jonathan Baron

1988/528 pp./34253-8/Hardcover $\$ 59.50$ 34800-5/Paper $\$ 22.95$

\section{The Child's Construction}

\section{of Economics}

Anna Emilia Berti and Anna Silvia Bombi with Gerard Duveen, translator

$1988 / 250$ pp. /33299-0/Hardcover $\$ 44.50$

\section{Similarity and Analogical}

Reasoning

Edited by Stella Vosniadou and

Andrew Ortony

1989/410 pp./36295-4/Hardcover $\$ 44.50$

\section{From Neuropsychology}

to Mental Structure

Tim Shallice

1988/464 pp. /30874-7/Hardcover \$59.50 31360-0/Paper $\$ 24.95$

\section{Children's Understanding \\ of Emotion}

Edited by Carolyn Saarni and Paul L. Harris

$1989 / 400$ pp. /33394-6/Hardcover about $\$ 42.50$

\section{The Construction Zone}

Working for Cognitive Change in School

Denis Newman, Peg Griffin and Michael Cole 1989/160 pp./36266-0/Hardcover \$22.95

\section{Rousing Minds to Life}

Teaching, Learning and Schooling in Social

\section{Context}

Roland G. Tharp and Ronald G. Gallimore

1989/336 pp./36234-2/Hardcover \$42.50

\section{Language, Memory and Aging}

Edited by Leah L. Light and Deborah M. Burke 1988/281 pp./32942-6/Hardcover $\$ 44.50$

\section{The Cognitive Structure}

\section{of Emotions}

Andrew Ortony, Gerald L. Clore and

Allan Collins

1988/175 pp./35364-5/Hardcover \$29.95

\author{
Computer Simulation in Brain \\ Science \\ Edited by Rodney M.J. Cotterill \\ 1989/576 pp./34179-5/Hardcover $\$ 65.00$
}

\section{The Cambridge Examination for} Mental Disorders of the Elderly Sir Martin Roth, F.A. Huppet, E. Tym and C.Q. Mountjoy

1988/35161-8/Boxed Set $\$ 95.00$

\section{The Selection of Behavior}

The Operant Behaviorism of B.F. Skinner:

Comments and Consequences

Edited by A. Charles Catania and

Stevan Harnad

1988/640 Pp./34388-7/Hardcover $\$ 75.00$ 34861-7/Paper $\$ 29.95$

\section{Developing Theories of Mind}

Edited by Janet W. Astington, Paul L. Harris and David $R$. Olson

$1988 / 512$ pp. $/ 35411-0 /$ Hardcover $\$ 44.50$

$$
\text { Now in paperback... }
$$

Piaget's Construction of the Child's Reality

Susan Sugarman

$1987 / 258$ pp. $/ 37967-9 /$ Paper about $\$ 14.95$

\section{How We Understand Art}

A Cognitive Developmental Account of Aesthetic Experience

Michael J. Parsons

1987/170 pp. /37966-0/Paper about $\$ 12.95$

Emotions, Cognition and Behavior Edited by Carroll E. Izard, Jerome Kagan and Robert B. Zajonc

$1984 / 632$ pp. / $31246-9 /$ Paper $\$ 29.95$

\section{Concepts and Conceptual Development \\ Ecological and Intellectual factors in \\ Categorization \\ Edited by Ulric Neisser \\ $1987 / 317$ pp./37875-3/Paper \$18.95}




\section{Behavioral and Brain Sciences}

\section{Instructions for Authors and Commentators}

Behavioral and Brain Sciences (BBS) is a unique scientific communication medium, providing the service of Open Peer Commentary for reports of significant current work in psychology, neuroscience, behavioral biology or cognitive science. If a manuscript is judged by BBS referees and editors to be appropriate for Commentary (see Criteria below), it is then circulated to a large number of commentators selected (with the aid of systematic bibliographic searches) from the BBS Associateship* and the worldwide biobehavioral science community, including individuals recommended by the author.

Once the Commentary stage of the process has begun, the author can no longer alter the article, but can respond formally to all commentaries accepted for publication. The target article, commentaries and authors' response then co-appear in BBS. Continuing Commentary and replies can appear in later issues.

Criterla for acceptance To be eligible for publication, a paper should not only meet the standards of a journal such as Psychological Review or the International Review of Neurobiology in terms of conceptual rigor, empirical grounding, and clarity of style, but it should also offer a clear rationale for sollciting Commentary. That rationale should be provided in the author's covering letter, together with a list of suggested commentators. The original manuscript plus elght coples must be submitted.

A paper for BBS can be (i) the report and discussion of empirical research that the author judges to have broader scope and implications than might be more appropriately reported in a specialty journal; (ii) an unusually significant theoretical article that formally models or systematizes a body of research; or (iii) a novel interpretation, synthesis, or critique of existing experimental or theoretical work. Occasionally, articles dealing with social or philosophical aspects of the behavioral and brain sciences will be considered.

The service of Open Peer Commentary will be primarily devoted to original unpublished manuscripts. However, a recently published book whose contents meet the standards outlined above may also be eligible for Commentary. In such a BBS Multiple Book Review, a comprehensive, article-length precis by the author is published together with the commentaries and the author's response. In special cases, Commentary will also be extended to a position paper or an already published article dealing with particularly influential or controversial research. Submission of an article implies that it has not been published or is not being considered for publication elsewhere. Multiple book reviews and previously published articles appear by invitation only. The Assoclateship and professlonal readership of BBS are encouraged to nominate current toples and authors for Commentary.

In all the categories described, the decisive consideration for eligibility will be the desirability of Commentary for the submitted material. Controversiality simpliciter is not a sufficient criterion for soliciting Commentary: a paper may be controversial simply because it is wrong or weak. Nor is the mere presence of interdisciplinary aspects sufficient: general cybernetic and "organismic" disquisitions are not appropriate for BBS. Some appropriate rationales for seeking Open Peer Commentary would be that: (1) the material bears in a significant way on some current controversial issues in behavioral and brain sciences; (2) it findings substantively contradict some wellestablished aspects of current research and theory; (3) it criticizes the findings, practices, or principles of an accepted or influential line of work; (4) it unifies a substantial amount of disparate research; (5) it has important cross-disciplinary ramifications; (6) it introduces an innovative methodology or formalism for consideration by proponents of the established forms; (7) it meaningfully integrates a body of brain and behavioral data; (8) it places a hitherto dissociated area of research into an evolutionary or ecological perspective; etc.

In order to assure communication with potential commentators (and readers) from other BBS specialty areas, all technlcal termlnology must be clearly defined or simplified, and speciallzed concepts must be fully described. Authors should use numbered section-headings to facilitate cross-reference by commentators.

Note to commentators The purpose of the Open Peer Commentary service is to provide a concentrated constructive interaction between author and commentators on a topic judged to be of broad significance to the biobehavioral science community. Commentators should provide substantive criticism, interpretation, and elaboration as well as any pertinent complementary or supplementary material, such as illustrations; all original data will be refereed in order to assure the archival validity of BBS commentaries. Commentaries and articles should be free of hyperbole and remarks ad hominem.
Style and format for articles and commentarles Articles must not exceed 14,000 words (and should ordinarily be considerably shorter); commentarles should not exceed 1,000 words. Spelling, capitalization, and punctuation should be consistent within each article and commentary and should follow the style recommended in the latest edition of $A$ Manual of Style. The University of Chicago Press. It may be helpful to examine a recent issue of BBS. A title should be given for each article and commentary. An auxiliary short title of 50 or fewer characters should be given for any article whose title exceeds that length. Each commentary must have a distinctive, representative commentary title. The contributor's name should be given in the form preferred for publication; the affiliation should include the full institutional address. Two abstracts, one of 100 and one of 250 words, should be submitted with every article. The shorter abstract will appear one issue in advance of the article; the longer one will be circulated to potential commentators and will appear with the printed article. A list of 5-10 keywords should precede the text of the article. Tables and figures (i.e. photographs, graphs, charts, or other artwork) should be numbered consecutively in a separate series. Every table and figure should have a title or caption and at least one reference in the text to indicate its appropriate location. Notes, acknowledgments, appendices, and references should be grouped at the end of the article or commentary. Bibliographic citations in the text must include the author's last name and the date of publication and may include page references. Complete bibliographic information for each citation should be included in the list of references. Examples of correct style for bibliographic citations are: Brown (1973); (Brown 1973); (Brown 1973; 1978); (Brown 1973; Jones 1976); (Brown \& Jones 1978); (Brown et al. 1979). References should be typed in alphabetical order in the style of the following examples. Journal titles should not be abbrevlated.

Kupfermann, I. \& Weiss, K. (1978) The command neuron concept. Behavioral and Brain Sciences 1:3-39.

Dunn, J. (1976) How far do early differences in mother-child relations affect later developments? In: Growing points in ethology, ed. P. P. G. Bateson \& R. A. Hinde. Cambridge University Press.

Bateson, P. P. G. \& Hinde, A. A., eds. (1976) Growing points in ethology. Cambridge University Press.

Preparation of the manuscript The entire manuscript, including notes and references, must be typed double-spaced on $81 / 2$ by 11 inch or A4 paper, with margins set to 70 characters per line and 25 lines per page, and should not exceed 50 pages. Pages should be numbered consecutively. It will be necessary to return manuscripts for retyping if they do not conform to this standard.

Each table and figure should be submitted on a separate page, not interspersed with the text. Tables should be typed to conform to BBS style. Figures should be ready for photographic reproduction; they cannot be redrawn by the printer. Charts, graphs, or other artwork should be done in black ink on white paper and should be drawn to occupy a standard area of $81 / 2$ by 11 or $81 / 2$ by $51 / 2$ inches before reduction. Photographs should be glossy black-and-white prints; 8 by 10 inch enlargements are preferred. All labels and details on figures should be clearly printed and large enough to remain legible even after a reduction to half size. It is recommended that labels be done in transfer type of a sans-serif face such as Helvetica.

Authors are requested to submit their double-spaced original manuscript with elght coples for refereeing, and commentators their original plus two copies, to: Stevan Harnad, Editor, Behavioral and Brain Sciences, 20 Nassau St., Suite 240, Princeton, NJ 08542. Electronic mail: harnad@princeton.edu or harnad@pucc.bitnet. Though not mandatory, ascii email versions or floppy disks of submissions (in addition to hard copies) facilitate processing. In case of doubt as to appropriateness for BBS commentary, authors should write to the editor before submitting eight copies.

Editing The publishers reserve the right to edit and proof all articles and commentaries accepted for publication. Authors of articles will be given the opportunity to review the copyedited manuscript and page proofs. Commentators will be asked to review copyediting only when changes have been substantial; commentators will not see proofs. Both authors and commentators should notify the editorial office of all corrections within $\mathbf{4 8}$ hours or approval will be assumed.

Authors of target articles receive 50 offprints of the entire treatment, and can purchase additional copies. Commentators will also be given an opportunity to purchase offprints of the entire treatment.

"Individuals interested in senving as BBS Associates are asked to write to the editor. 


\section{To appear in Volume 12, Number 4 (1989)}

Offprints of the following forthcoming BBS treatments can be purchased for educational purposes if they are ordered well in advance. For ordering information, please write to Journals Department, Cambridge University Press, 40 West 20th Street, New York, NY 10011.

\section{On the function of muscle and refiex partitioning \\ Uwo Windhorst, Thomas M. Hamm \& Douglas G. Stuart, Universinat Gostingen, St. Josoph's Hospital and Modical Conter and University of Arizona}

Localized stretch reflexes, the partitioning of sensory output from muscles and the partitioning of segmental pathways to motor nuclei have been demonstrated in the mammalian neuromuscular system. This suggests that individual motor nuclei and the muscles they innervate are not homogeneous functional units. Functional analysis of reflex localization and partitioning suggests that segmental control mechanisms are bosed on subdivisions of motor nuclei-muscle com. plexes. A partitioned organization of segmental control mechanisms may provide a number of functional advantages for the control of neuromuscular systems with complex structure and organization.

Whth Commentary from JH Abbs \& BB Edin; U Bässler; RE Burke; F Delcomyn; J Duysens; SC Gandevia; CCAM Gielen; GE Loeb \& FJR Richmond; PBC Matthews; JB Munson \& RC Foehring; G Székely; and others.

\section{Selfishness examined: Cooperation in the absence of egoistic incentives LInnda R. Caporael, Robyn M. Dawes, John M. Orbell a Alphons J. C. van de Kragt, Renssolaer Polytechnic Instifute, Carmegio-Mollon University, University of Oregon, and University of Manitioba}

Social dilemmas occur when the pursuit of self-interest by individuals in a group leads to collective outcomes for everyone in the group that no individual desires. According to "economic man" and "selfish gene" theories, such dilemmas can only be resolved on the basis of selfish incentives. This claim was not supported in a series of experimental social dilemmas in which subjects made single, anonymous choices about whether or not to contribute money for a shared "bonus" that they would get only if enough other people in the group also chose to contribute their money. The findings suggest that the mechanisms underlying such behavior were shaped by evolutionary pressures on small groups. Whth Commentary from T Caraco; N Eldredge; CS Findlay \& CJ Lumsden; GM Heyman; AI Houston \& WD Hamilton; D Krebs; S Oyama; H Rachlin; A Rapoport; SC Stearns; NC Stenseth; J Tooby \& L Cosmides; and others.

\section{Mulitiple book reviow of Speech perception by oar and eye: A paradigm for psychological inquiry \\ Dominic W. Massaro, Univorsity of Callfomia}

This book is about the processing of information in face-to-face communication. Auditory and visual sources of informa. tion are evaluated and integrated to achieve speech perception. Perceivers evaluate each source independently of other sources to obtain a continuous measure of support for each viable alternative interpretation of the stimulus. The integration process follows an optimal algorithm in which the least ambiguous sources have the greatest impact on performance. These processes occur in a similar fashion through development and aging. Performance differences across the lifespan can be accounted for by different amounts of information. These findings about speech perception also apply to personality judgments, categorization, sentence interpretation, and decision making

With Commentary from MH Bornstein; RG Crowder; B de Gelder \& J Vroomen; G Ehret; G Gigerenzer; S Glucks. berg; LE Krueger; DG MacKay; RF Port; M Studdert-Kennedy; JT Townsend; RM Warren; RB Welch; F Wilkening; and others.

\section{Among the articles to appear in fortheoming lasues of BAS:}

J Schull, "Are species intelligent?"

R Näätänen, "Role of attention in auditory information processing revealed by event-related brain potentials"

JC Prechtl \& TL Powley, "B-Afferents: A fundamental division of the nervous system"

MS Dawkins, "From an animal's point of viow: Motivation, fitness, and animal welfare," With Precommentary from

P Singer, "The significance of animal suffering"

D Wahlsten, "Insensitivity of the analysis of varionce to heredity-environment interaction"

SJ Hanson \& DJ Burr, "What connectionist models learn: Learning and repesentation in connectionist networks"

JK Tsotsos, "Analyzing vision at the complexity level"

D Falk, "Brain evolution in Homo: The "radiator theory" 